content of client and healthcare worker interactions and documentation. The checklist complemented STI care focussed EPR proformas, significantly improved communication modalities and was especially valued by staff and clients new to the service.

\section{P127 \\ HIV TESTING: ARE THE TARGETS OFF TARGET?}

Sophie Russell*, Stuart Vernon, Amy Carson, Danielle Harris, Helen Wheeler. University Hospitals Bristol NHS Foundation Trust, Bristol, UK

\subsection{6/sextrans-2016-052718.181}

Background/introduction The British Association for Sexual Health and HIV (BASHH) standards provide clear targets for HIV testing in genitourinary medicine (GUM). BASHH state that $97 \%$ of people with 'needs relating to STIs' are offered an HIV test at first attendance; and that $80 \%$ are recorded to have an HIV test. Public Health England place testing figures for our fully integrated sexual and reproductive health service consistently below recommended standards.

Aim(s)/objectives To establish true HIV testing rates within an urban sexual health clinic, and to explore factors contributing to our performance.

Methods Electronic patient records from all attendances to GUM or contraception and sexual health clinics between 02/03/ 2015 and 06/03/2015 were analysed to establish rates and patterns of HIV testing.

Results 282 patients were included in analysis; 253 (89.7\%) were offered an HIV test, and 176 (62.3\%) had a test. 77 patients refused an HIV test; the most common documented reason was self/clinician perceived low risk (22). Within the 'high risk' cohort (52) only four refused and the reason was clearly noted. If patients attending primarily for contraceptive care were excluded from analysis, 225 patients remained; of these 211 (93.7\%) were offered an HIV test and 164 (72.9\%) had a test.

Discussion/conclusion We suggest that our lower testing rates, in part, reflect the inclusion of patients attending primarily for contraceptive care. In all sexual health/contraceptive clinics it remains important to risk assess patients, and offer HIV testing where appropriate, but our analysis begs the question: should the targets be amended for fully integrated services?

\section{P128 HUMAN PAPILLOMAVIRUS (HPV) VACCINATION IN YOUNG MEN WHO HAVE SEX WITH MEN (MSM) IN THE UK. AN ONLINE SURVEY OF ATTITUDES, INTENTIONS AND OPINIONS AMONG MSM OFFERED VACCINATION WITHIN INTEGRATED SEXUAL HEALTH SERVICES}

John McSorley*, Tapiwa Zhou, Patrick Kuria, Moses Kapembwa, Gary Brook. London North West Healthcare NHS Trust, London, UK

\subsection{6/sextrans-2016-052718.182}

Background We have offered quadrivalent HPV vaccine (HPV4) to MSM under 27 years since 2012. We have observed a 60\% 3 dose completion rate within 1 year.

Aims (1) To identify motivating factors or barriers influencing HPV4 completion in a cohort of MSM receiving at least one dose of HPV vaccine. (2) To identify factors influencing survey response rates.

Methods An email and reminder and an SMS text weblink to an online survey was sent to all MSM who received at least 1 dose of HPV4 vaccine.
Results Of 893 eligible, 688 (77\%) had an email address, 257 (29\%) opened the survey, and 228 (26\%) completed the survey. $89 \%$ respondents learned of the vaccine at offer. $87 \%$ were happy with the information received and 97\% with their decision to accept vaccine. A reminder strategy utilising SMS text for 1 year was preferred. Prevention of genital warts and anogenital cancers were equally highly important in motivation. Trusted healthcare workers were important influences in decision making

\begin{tabular}{|c|c|c|c|c|c|c|c|}
\hline \multicolumn{3}{|c|}{ Abstract P128 Table 1} & \multicolumn{5}{|c|}{ Sample questions and summary responses } \\
\hline What's & $\mathrm{GW}^{*}$ & $\mathrm{GW}^{*}$ & $\mathrm{GW}^{*}$ & AIN/AC* & AIN/AC* & AIN/AC* & Agreeing \\
\hline important & $\mathrm{Me}$ & My & Population & $\mathrm{Me}$ & My & Population & with \\
\hline for & $4.2 / 5$ & partner & $3.8 / 5$ & $4.2 / 5$ & partner & $3.8 / 5$ & $\mathrm{HCW}^{*}$ \\
\hline Prevention? & & $4.1 / 5$ & & & $4.1 / 5$ & & $2 / 5$ \\
\hline \multicolumn{8}{|l|}{ Score/5 } \\
\hline GW & Yes & No $73 \%$ & Not sure & GW & Yes $4 \%$ & No $95 \%$ & Not sure \\
\hline before? & $22 \%$ & & $4 \%$ & since? & & & $2 \%$ \\
\hline AIN/AC & Yes & No $96 \%$ & Not sure & AIN/AC & Yes $0.3 \%$ & No $99 \%$ & Not sure \\
\hline before? & $3 \%$ & & $1 \%$ & since? & & & $1 \%$ \\
\hline Who could & Sexual & Friend & Primary & Schools & Twitter & Youtube & LGBT+ \\
\hline influence & Health & thro' & Care & Campaign & Campaign & Campaign & Media \\
\hline \multirow[t]{2}{*}{ MSM? } & $80 \%$ & Facebook & Team & $53 \%$ & $51 \%$ & $40 \%$ & $40 \%$ \\
\hline & & $74 \%$ & $65 \%$ & & & & \\
\hline
\end{tabular}

${ }^{*} \mathrm{GW}=$ genital warts, AIN/AC = anal intra-epithelial neoplasia/anogenital cancer HCW $=$ Health Care Worker

Survey respondents were more likely to be older (>21 yrs), HIV positive, homosexual and of non-white british ethnicity than the cohort of vaccine recipients.

Discussion MSM HPV vaccine recipients express high levels of satisfaction with vaccination despite little a priori awareness. Trusted public service providers \& friends are influential. Completion should be supported through a multifaceted approach involving a range of agencies and media and expansion of access to vaccine.

\section{P129 HOW COMMON IS MYCOPLASMA GENITALIUM? SYSTEMATIC REVIEW AND META-ANALYSIS}

${ }^{1}$ Lukas Baumann, ${ }^{1}$ Manuel Cina, ${ }^{1}$ Myrofora Goutaki, ${ }^{1}$ Florian Halbeisen, ${ }^{2}$ Hammad Ali, ${ }^{1}$ Fabio Giudici, ${ }^{1}$ Dianne Egli-Gany, ${ }^{1}$ Nicola Low*. 'University of Bern, Bern, Switzerland; ${ }^{2}$ University of New South Wales, Sydney, Australia

\subsection{6/sextrans-2016-052718.183}

Background Mycoplasma genitalium is a common cause of nongonococcal non-chlamydial urethritis but prevalence rates in asymptomatic populations are not well-established.

Objectives To estimate the prevalence of M. genitalium in adult women and men in general population and clinic based samples. Methods We searched Embase, Medline, IndMED, AIM and LILACS. We examined eligible studies in forest plots and conducted random effects meta-analysis if appropriate. Between study heterogeneity was examined by use of the $\mathrm{I}^{2}$ statistic.

Results Of 4355 screened abstracts, 55 studies were eligible. In high income countries that described samples from the general population, prevalence estimates ranged from 0.5 to $3.3 \%$ (pooled prevalence 1.4\% (95\% confidence intervals, CI 0.9 to $\left.1.9 \%, \mathrm{I}^{2} 72.2 \%\right)$. In three studies with population-based random sampling prevalence was $1.2 \%$ (95\% CI 0.9 to $\left.1.6 \%, \mathrm{I}^{2} 30.1 \%\right)$. 